\title{
OPEN Physical activity, screen exposure and sleep among students during the pandemic of COVID-19
}

\author{
Yang-feng Guo ${ }^{1}$, Min-qi Liao ${ }^{2}$, Wei-li Cai ${ }^{1}$, Xiao-xuan $\mathrm{Yu}^{2}$, Shu-na $\mathrm{Li}^{2}$, Xing-yao Ke ${ }^{2}$, \\ Si-xian Tan' ${ }^{2}$, Ze-yan Luo ${ }^{2}$, Yun-feng Cui ${ }^{2}$, Qian Wang ${ }^{2}$, Xu-ping Gao ${ }^{3}$, Jun Liư ${ }^{4}$, Yan-hua Liu ${ }^{5}$, \\ Sui Zhu ${ }^{6}$ \& Fang-fang Zeng ${ }^{2 \bowtie}$
}

This study aimed to determine the levels of health-related behaviours (physical activity, screen exposure and sleep status) among Chinese students from primary, secondary and high schools during the pandemic of COVID-19, as well as their changes compared with their status before the pandemic. A cross-sectional online survey of 10,933 students was conducted among 10 schools in Guangzhou, China, between 8th and 15th March, 2020. After getting the informed consent from student's caregivers, an online questionnaire was designed and used to obtain time spending on health-related behaviours during the pandemic of COVID-19, as well as the changes compared with 3 months before the pandemic, which was completed by students themselves or their caregivers. Students were stratified by regions (urban, suburban, exurban), gender (boys and girls), and grades (lower grades of primary school, higher grades of primary schools, secondary schools and high schools). Data were expressed as number and percentages and Chi-square test was used to analyse difference between groups. Overall, the response rate of questionnaire was $95.3 \%(10,416 / 10,933)$. The median age of included students was $13.0(10.0,16.0)$ years and $50.1 \%(n=5,219)$ were boys. $41.4 \%, 53.6 \%$ and $53.7 \%$ of total students reported less than $15 \mathrm{~min}$ per day in light, moderate and vigorous activities and $58.7 \%(n=6,113)$ reported decreased participation in physical activity compared with the time before pandemic. Over $5 \mathrm{~h}$ of screen time spending on online study was reported by $44.6 \%(n=4,649)$ of respondents, particular among high school students (81.0\%). 76.9\% of students reported increased screen time compared with the time before pandemic. Inadequate sleep was identified among $38.5 \%$ of students and the proportion was highest in high school students (56.9\%). Our study indicated that, during the COVID-19 pandemic, the school closure exerted tremendous negative effects on schoolaged children's health habits, including less physical activity, longer screen exposure and irregular sleeping pattern.

The 2019 novel coronavirus disease (COVID-19) is an emerging disease caused by sever acute respiratory syndrome coronavirus 2 (SARS-CoV-2), firstly occurred in Wuhan, Hubei province, China, in December, 20191 . As of March 06, 2021, the outbreak of COVID-19 has spread to 223 countries, areas or territories, affected almost 115.3 million individuals, and caused over 2.56 million deaths worldwide ${ }^{2}$. School closures and other school social distance interventions were deployed rapidly across China and other 106 countries to prevent rapid transmission of the disease by March 18,2020,4. Therefore, due to restriction of group activities, team sports or playgrounds, there were more than 220 million children and adolescents, including 180 million primary and secondary students and 47 million preschool-aged children, had to be confined at home during the pandemic of COVID-19 in China 5 .

\footnotetext{
${ }^{1}$ Department of Common Chronic Disease Control and Prevention, Health Promotion Centre for Primary and Secondary Schools of Guangzhou Municipality, Guangzhou 510630, China. ${ }^{2}$ Department of Epidemiology, School of Medicine, Jinan University, No.601 Huangpu Road West, Guangzhou 510630, China. ${ }^{3}$ Department of Child \& Adolescent Psychiatry, National Clinical Research Centre for Mental Disorders \& Key Laboratory of Mental Health, Ministry of Health (Peking University), Peking University Sixth Hospital (Institute of Mental Health), No.51 Huayuan Bei Road, Beijing 100191, China. ${ }^{4}$ Preventive Medicine Experimental Teaching Centre, Zunyi Medical University, No.6 Xuefu West Road, Zunyi 564699, Guizhou Province, China. ${ }^{5}$ Department of Nutrition, The First Affiliated Hospital of Zhengzhou University, Zhengzhou 450052, China. ${ }^{6}$ Department of Medical Statistics, School of Medicine, Jinan University, No.601 Huangpu Road West, Guangzhou 510630, China. ${ }^{凶}$ email: zengffju@@126.com
} 
Although decreased transmission of SARS-CoV-2 has been found to be associated with the conduction of non-pharmaceutical interventions (NPIs) including school closure ${ }^{6}$. However, closing schools may also have downsides. Evidence suggested that student's connection with classmates and opportunities for physical activity might greatly reduce by the enforced isolation and school closure ${ }^{7,8}$. Furthermore, children's sedentary activities and screen time might expand owing to the social distancing ${ }^{7}$. Moreover, because the online courses were delivered through TV broadcasts or internet, school-aged children had to learn online using digital devices, which might exacerbate the overuse of media applications among children ${ }^{4}$. Besides, caregivers should pay attention to children's sleeping status since evidence showed that sleep difficulties and nightmares might be attributable to the fears, uncertainties, physical and social isolation during the period staying at home ${ }^{8}$.

Till now, despite several studies have reported the challenges of COVID-19 pandemic for students, most of them highlighted the potential impact of the terrible COVID-19 outbreak on the mental health ${ }^{9,10}$, as well as its impact on education ${ }^{11,12}$ of university students, rather than primary, secondary and high school students. A recent study has observed worsened health-related behaviours (HRBs) among Spanish children and adolescents (aged 3 to 16 years) during the home confinement of COVID-19, including a significant reduction in physical activities, increased hours of screen exposure, as well as decreased daily consumptions of fruits and vegetables ${ }^{13}$. However, the self-reported data of 860 recruited children and adolescents in this study was totally obtained from 516 parents by online survey ${ }^{13}$, which might have significant recall bias because the physical activity, screen, and dietary data reported by children or adolescents might be different with the data obtained from their parents ${ }^{14}$. Further studies with larger sample size are needed to clarify the conditions of health-related behaviours among isolated students during the pandemic of COVID-19.

Hence, this study is designed to describe the status and changes in the levels of health-related behaviours (physical activity, screen exposure and sleep status) among Chinese students during school closures during the pandemic of COVID-19, in order to call attention to the potential adverse effects of school closure on student's health.

\section{Methods}

Study design and participants. This descriptive cross-sectional survey was conducted in three regions (urban, suburban, and exurban) of Guangzhou, China, which represented regions with high-income, middleincome, and relatively lower-income, from 8 March 2020 to 15 March 2020. Convenience sampling was applied to obtain representative samples of primary, secondary, and high schools. The recruitment procedures included: (i) identifying potentially eligible schools via checking the records in the system including all of the schools in Guangzhou; (ii) sending an invitation letter to the targeted schools with description of the survey; (iii) telephoning the principals or deans of targeted schools to get their consent and supports; (iv) sending the link of our questionnaire to the head teachers; and (v) then sending the link to student's caregivers by the head teachers and inviting them to participate in the survey. The exclusion criteria included: (i) students whose caregivers refused to fulfil the questionnaire; (ii) questionnaires were fulfilled within 200 seconds; and (iii) students reported BMI $>35 \mathrm{~kg} / \mathrm{m}^{2}$ or $<10 \mathrm{~kg} / \mathrm{m}^{2}$. Finally, 10 schools, including 4 urban schools (2 primary and 2 secondary and high schools in Liwan district), 3 suburban schools (2 primary and 1 secondary and high schools in Panyu district) and 3 exurban schools ( 2 primary and 1 secondary and high schools in Zengcheng district), were included in the present study.

Ethics approval in accordance with the Declaration of Helsinki was obtained from the ethics committee of Health Promotion Centre for Primary and Secondary Schools of Guangzhou Municipality (No. 202001). The electronic informed consent was obtained from students or their caregivers before the survey.

Data collection. Due to the social distancing measures and restricted movement, all the data were collected online by using a professional questionnaire App (Wenjuanxing). A structured questionnaire was designed and distributed through WeChat, the most popular instant messaging platform in China ${ }^{15}$. After getting the informed consent, the questionnaires for students from primary schools were mainly completed by their major caregivers (i.e., parents/other guardians), and questionnaires for students from secondary and high schools were directly fulfilled by students themselves under the supervision of their caregivers. The questionnaire was filled out anonymously. The structured questionnaire included four sections: (i) socio-demographic characteristics of the students (i.e., age, sex, school districts, grades, and monthly family income); (ii) the current status of student's physical activity, screen exposure, and sleeping duration during the pandemic of COVID-19; and (iii) their changes compared to 3 months before the outbreak of COVID-19.

Physical activity. The daily duration of physical activity was assessed with the question: "During the COVID19 pandemic, how long does you (or your child) spend in doing light (i.e., walking and jogging), moderate (i.e., brisk walking, slow jogging and cycling) and vigorous activities (i.e., running, skipping and swimming) daily on average?" The answers were categorized into four groups: "0-15 min/day", "16-30 $\mathrm{min} /$ day", "31-60 $\mathrm{min} /$ day", and "> $60 \mathrm{~min} /$ day". The change in physical activity was assessed with the question "Compare with the three months before the outbreak of COVID-19, is there any difference in time you (or your child) spend on daily physical activity?" The categorical answers were recoded as "Increase", "No difference" and "Decrease".

Screen exposure. The daily duration of screen exposure was assessed with the question: "How long does you (or your child) spend in using digital devices for ... on average", followed by 3 items of purposes, including "Study (attending online courses and finishing digital homework)", "Amusement (playing computer/mobile games)" and "Leisure (chatting, reading, watching video)". The question, "Compare with the 3 months before the outbreak of COVID-19, is there any difference in daily time you (or your child) spend in using screen-based 
medias (i.e., cell phone, computer or pad)?" was responded by answers involved "Appreciably increase", "Slightly increase", "No difference" and decrease ("Slightly increase" and "Appreciably decrease").

Sleep pattern. The question, "During the COVID-19 pandemic, how long does you (or your child) sleep (including napping) daily?" was followed by the answers ranged from 5.0 to $14.0 \mathrm{~h} /$ day, at an interval of $0.5 \mathrm{~h}$. According to the recommended of the American Academy of Sleep Medicine (AASM), sleep for 9-12 h/day and $8-10 \mathrm{~h} /$ day on a regular basis could promote the optimal health for children aged 6-12 years and teenagers aged 13-18 years, respectively ${ }^{16}$. Hence, the options included "Inadequate sleep", "Adequate sleep" and "Excessive sleep" according to age and self-reported sleeping duration. Likewise, the questionnaire "Compare with the three months before the outbreak of COVID-19, is there any change in the amount of you (or your child) daily sleeping?" was followed by the answers "Increase", "No difference" and "Decrease".

Statistical analysis. All data was entered, cleaned, and checked for missing values and outliers by two research assistants. Categorical variables were presented as number and percentages. Chi-square test was used to analyse difference between groups. All 12 grades were categorized into four groups: lower grades of primary school (grades 1-3), higher grades of primary school (grades 4-6), secondary school (grades 7-9) and high school (seniors 1-3). Stratified analyses were conducted to examine changes between groups according to school districts, sex, and grades. All data were analysed by using R-3.5.1 (R Development Core Team, Vienna, Austria) software and the statistically significant difference was identified as a two-side $P$ value $<0.05$.

Ethics approval and consent to participate. Ethics approval was obtained from the ethics committee of Health Promotion Centre for Primary and Secondary Schools of Guangzhou Municipality (No. 202001). Electronic informed consent from all the participants was obtained before the survey.

\section{Results}

Basic characteristics of included participants. The flow chart of participants selection is shown in Fig. 1. A total of 10,933 students/caregivers were successfully invited to complete the online survey. After excluding the unqualified questionnaire, 10,416 (95.3\%) were included in the final analysis. The proportion of boys $(5,219 / 10,416,50.1 \%)$ was slightly higher than girls $(5,197 / 10,416,49.9 \%) .37 .1 \%, 35.3 \%$ and $27.6 \%$ were from urban, suburban, and exurban areas in Guangzhou. 23.2\%, 22.4\%, 28.9\% and 29.7\% of students came from lower, higher grades of primary schools, secondary schools, and high schools. Significant differences were observed in gender, grades, and family income across regions (all $P$ values $<0.05$ ) (Table 1 ).

Physical activity. As shown in Table 2 and Supplementary Fig. S1, 41.4\% of total students reported " $16-30 \mathrm{~min} /$ day" for light activity and $53.6 \%$ and $53.7 \%$ of students reported only " $0-15 \mathrm{~min} /$ day" for moderate and vigorous activities. Of three different regions, the percentages of students who participated in light, moderate and vigorous activities for less than $15 \mathrm{~min}$ per day were both highest in suburban area (34.6\%, 56.9\% and 56.1\%), but for more than 60 min per day were consistently lowest in this area (5.5\%, 3.5\% and $4.1 \%)$.

When further stratification by sex and grades, we found that the percentages of those who participated in activities for less than 15 min per day were higher among girls (33.1\%, 55.1\%, and 56.8\%) than that of boys $(32.2 \%, 52.1 \%$, and $50.5 \%)$. About $67.7 \%$ and $71.1 \%$ of high school students reported $<15 \mathrm{~min} /$ day spending in moderate and vigorous activities, which were higher than the proportions of other three grades (Table 2, Supplementary Figs. S1-S3).

In Supplementary Table S1, more than half of students (58.7\%) reported decreased time participating in physical activity after the outbreak of COVID-19, especially for those who came from the suburban area (64.8\%; Fig. 2, Supplementary Fig. S4). After being stratified by sex and grades, we found that boys tended to report decreased time spending on physical activity compared than that of girls, particularly in suburban area (boys: $65.5 \%$ vs. girls: $63.2 \%$ ). Besides, we noticed that the prevalence of students who reported decreased time on physical activity was mostly came from high school (66.9\%; Supplementary Fig. S5). Especially, the proportion of high school students who reported decreased time in physical activity was highest in exurban area (69.9\%).

Screen exposure. As shown in Table 3, 44.6\% of total students reported over $5 \mathrm{~h}$ of screen time on online study each day during the pandemic of COVID-19, particularly among students came from urban area (48.2\%). In addition, $35.0 \%$ and $49.9 \%$ of students reported 1 to $2 \mathrm{~h}$ of screen time for amusement and leisure, particularly in exurban area (38.4\% and 51.9\%) (Supplementary Fig. S6). Subgroup analyses suggested that proportion of students who reported more than $5 \mathrm{~h}$ for online study per day was higher among girls than that of boys $(48.8 \%$ vs. $41.3 \%)$ and these proportions were highest in urban area (52.2\% for girls and $43.8 \%$ for boys).

Screen time increased with grades, particularly the time for online study and leisure (Supplementary Fig. S7). Only $7.0 \%$ of low-grade primary school students spent over $5 \mathrm{~h}$ /day on online study, but the proportion increased to $81.0 \%$ for students from high schools. In addition, about $27.2 \%$ of low-grade primary school students spent 1 to $2 \mathrm{~h}$ for amusement and $44.5 \%$ for leisure daily, but the proportions increased to $37.2 \%$ and $53.9 \%$ among high school students (Table 3).

In Supplementary Table S2, nearly $80.0 \%$ of students reported increased screen exposure after the outbreak of COVID-19. $36.0 \%$ of students reported "appreciably increased" screen time and $40.9 \%$ reported "slightly increased" screen time, particularly among students from urban area (38.4\% and 39.9\%; Fig. 2, Supplementary Fig. S8). In stratified analyses, slightly higher proportion of girls reported increased screen time than that of boys (78.1\% vs. $75.8 \%)$. Additionally, the highest proportion of students who reported "appreciably increased screen 

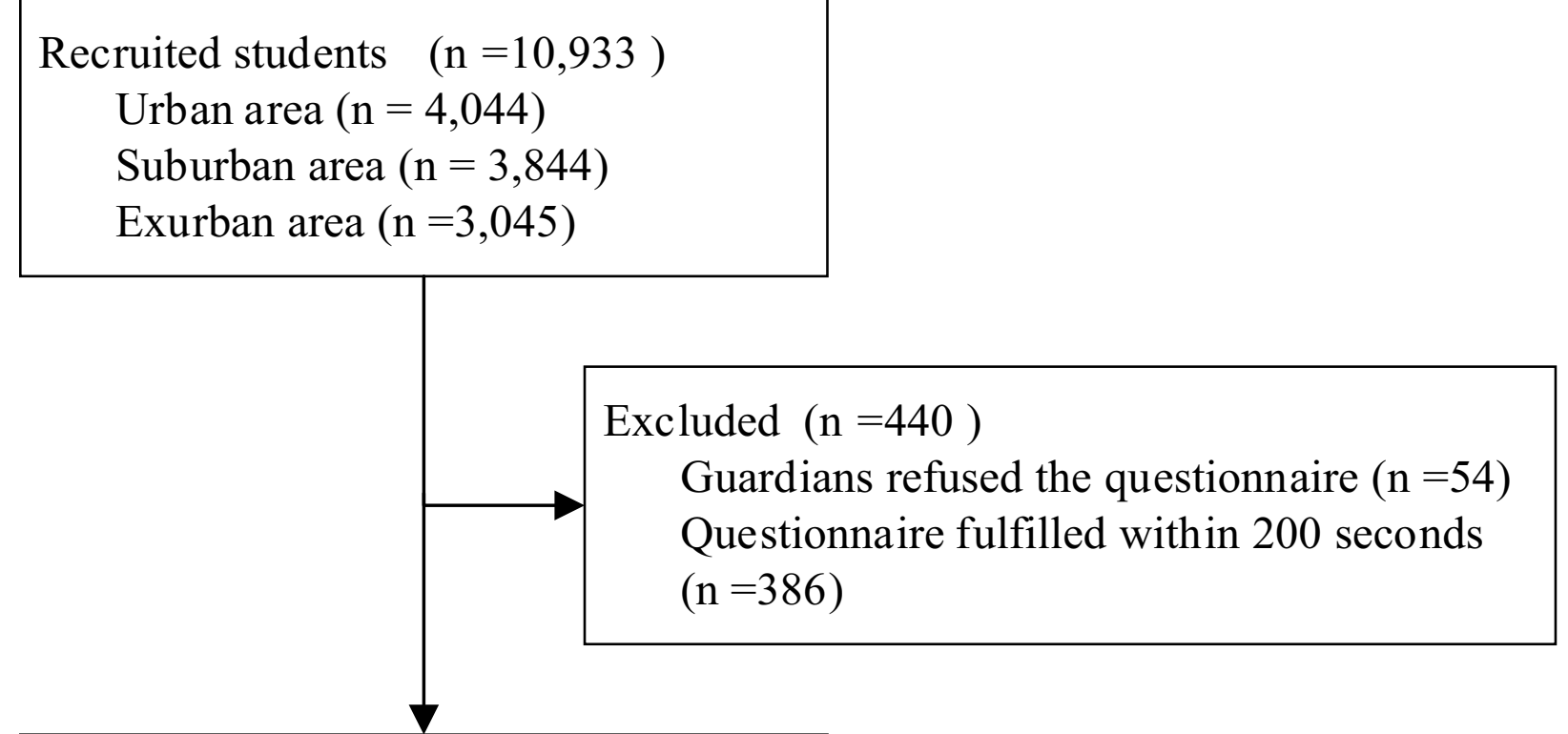

\section{Potential eligible students $\quad(n=10,493)$}

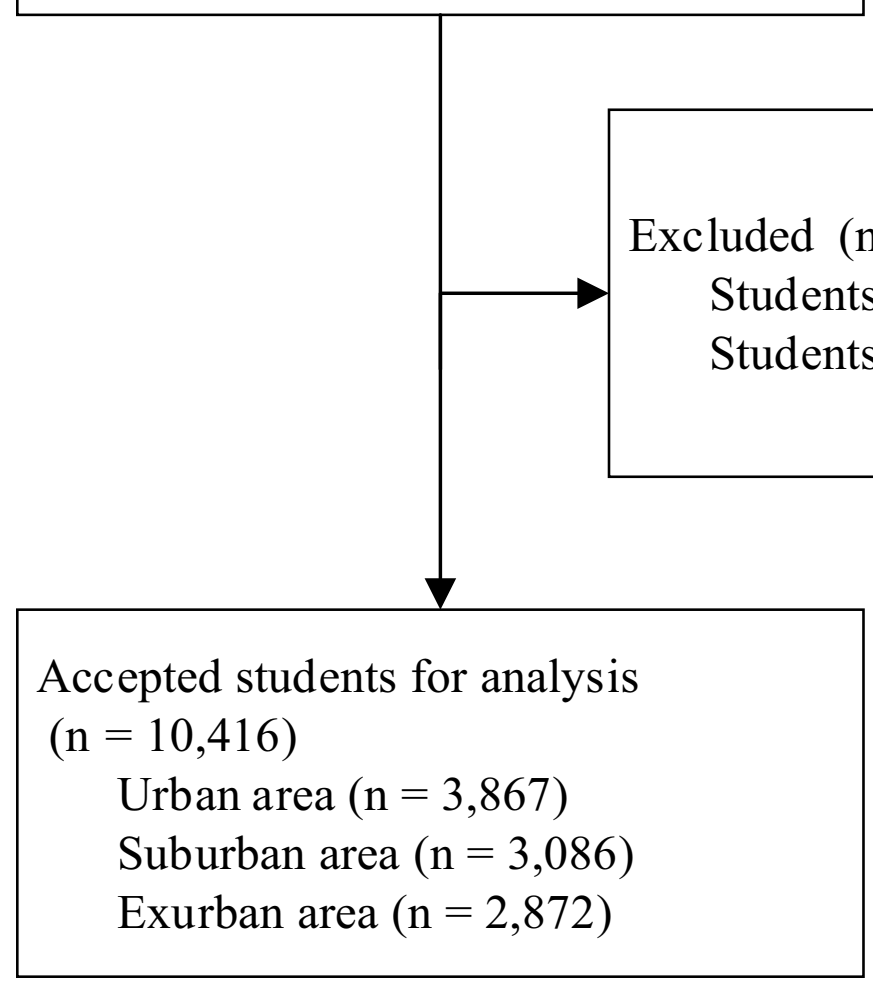

Figure 1. The selection procedure of participants.

time" was among high school students (44.7\%), but the proportion of students reported "slightly increased" screen time was highest in students from lower grades of primary schools (Supplementary Fig. S9).

Sleep duration. As shown in Table 4, 38.5\% of students reported inadequate sleep, whereas only $2.1 \%$ of students were categorized into "Excessive sleep". This proportion was highest in those from urban area (41.5\%) and lowest in suburban area (33.5\%) (Supplementary Fig. S10). Higher proportion of girls reported inadequate sleep duration than that of boys (40.0\% vs. 37.0\%) (Supplementary Fig. S11). When stratified by grades, the highest proportion of students with inadequate sleep was reported by high school students $(56.9 \%)$, while the lowest prevalence was reported by lower grades of primary school students $(26.1 \%)$. 


\begin{tabular}{|c|c|c|c|c|c|}
\hline & \multicolumn{4}{|c|}{ Number of participants (\%) } & \multirow[b]{2}{*}{$P$ value $^{\mathrm{a}}$} \\
\hline & Overall & Urban area & Suburban area & Exurban area & \\
\hline Total sample size & $10,416(100.0)$ & $3867(37.1)$ & $3677(35.3)$ & $2872(27.6)$ & \\
\hline \multicolumn{5}{|l|}{ Sex } & 0.001 \\
\hline Boys & $5219(50.1)$ & $1870(48.4)$ & $1831(49.8)$ & $1518(52.9)$ & \\
\hline Girls & $5197(49.9)$ & $1997(51.6)$ & $184650.2)$ & $1354(47.1)$ & \\
\hline \multicolumn{5}{|l|}{ Grades levels } & $<0.001$ \\
\hline Lower grades of primary school ${ }^{b}$ & $2279(23.2)$ & $952(24.6)$ & $700(22.7)$ & $627(21.8)$ & \\
\hline Higher grades of primary school $^{c}$ & $2204(22.4)$ & $924(24.9)$ & $731(23.7)$ & $549(19.1)$ & \\
\hline Secondary school & $2843(28.9)$ & $957(24.7)$ & $822(26.6)$ & $1064(37.0)$ & \\
\hline High school & $3090(29.7)$ & $1034(26.7)$ & $142438.7)$ & $632(22.0)$ & \\
\hline \multicolumn{5}{|l|}{ Family income (yuan/month) } & $<0.001$ \\
\hline$\leq 2000$ & $523(5.0)$ & $145(3.7)$ & $111(3.0)$ & $267(9.3)$ & \\
\hline $2001-5000$ & $2462(23.6)$ & $753(19.5)$ & $738(20.1)$ & $971(33.8)$ & \\
\hline $5001-10,000$ & $2422(23.3)$ & $877(22.7)$ & $948(25.8)$ & $597(20.8)$ & \\
\hline$>10,000$ & $1673(16.1)$ & $664(17.2)$ & $751(20.4)$ & $258(9.0)$ & \\
\hline
\end{tabular}

Table 1. Characteristics of students in various regions of Guangzhou during the COVID-19 pandemic. All data are presented as frequency and its percentage. ${ }^{a} P$ values were calculated by Chi-square test. ${ }^{b}$ Lower grades of primary school: grades 1 st to $3 \mathrm{rd}$ in primary school. ${ }^{c}$ Higher grades of primary school: grades 4 th to 6 th in primary school.

As shown in Supplementary Table S3 and Fig. 2, 35.7\% of students reported increased sleeping duration since the outbreak of COVID-19, whereas $16.8 \%$ of students reported decreased sleep duration. The highest proportions of students with increased and decreased sleeping duration were observed in suburban area (41.9\%) and exurban area (21.2\%) (Supplementary Fig. S12). Generally, the proportion of students who reported increased sleep duration decreased with increased grades (lower grades of primary school students: $40.4 \%$ vs. high school students: $31.5 \%$ ), whereas inverse trend was observed for reduced sleeping time (lower grades of primary school students: $11.6 \%$ vs. high school students: 24.7\%) (Supplementary Fig. S13).

\section{Discussion}

In this cross-sectional study, we observed significant decreased time spent on physical activity, longer screen time, and abnormal sleeping duration among primary, secondary and high school students during or compared with three months before the outbreak of COVID-19. Of note, we noticed that these unhealthy lifestyles occurred more frequently among students in higher grades and those from urban area.

Recently, Moore et al. ${ }^{17}$ found that less than $5.0 \%$ of children and only $0.6 \%$ of youths across Canada met the combined movement behaviour guidelines during the initial period of COVID-19 crisis. They also reported more sedentary and screen-based activities and longer sleeping time among children and adolescents compared with before the school closure ${ }^{17}$. Another study conducted in Spain consistently reported that school closure might worsen most health-related behaviours (reduced physical activity and increased screen time and sleep time among school-aged children and adolescents ${ }^{13}$. However, both two studies were totally based on parentreported data, the possibility of social desirability and recall bias could affect their findings. An international study conducted among 726 adolescents aged 16-19 years old from Europe (Italy and Spain) and Latin America (Brazil, Chile, and Colombia) reported reductions of physical activity during the pandemic ${ }^{18}$. Nevertheless, this study was based on a convenience sample from different countries and their findings could not generalize to the entire population from those places.

During the pandemic of COVID-19, the confinement at home with reduced opportunities for physical activity, thus the levels of physical activity significantly decreased among students ${ }^{7}$. Participations in team sports and activity at recess might benefit to the well-being of students and promote the prosocial behaviour and counteract disaffection in adolescents ${ }^{19,20}$. Physical education classes might play an important role in helping youth attain sufficient levels of physical activity during school time. However, the access to physical activity and the all these activity-related benefits would be diminished due to the prolonged school closure ${ }^{21}$. Most of children in urban area were forced to stay at home and their engagement in activities outdoor, such as in parks and playgrounds, would be limited by their caregivers since they could not ensure that these places were clean and safe enough ${ }^{7}$. Of note, the physical activity engagement among high school students might be lower than that of lower grade students due to their heavier educational burden. Previous studies consistently showed that student's physical inactivity might increase with age and education levels ${ }^{22,23}$. Physical activity may appeal more to boys rather than girls $^{22}$, exacerbating the sex disparity of self-reported decline in physical activity. Insufficient physical activity might affect the growth and development of children and adolescents, leading to several adverse consequences such as elevated insulin and blood lipids level ${ }^{24}$, obesity ${ }^{25}$, coronary heart disease and cancers ${ }^{26}$, or mental outcomes such as poor social behaviour ${ }^{20}$ and depression ${ }^{27}$. Thus, maintaining regular physical activity in a safe environment need to be promoted for healthy living during the $\mathrm{crisis}^{28}$. 


\begin{tabular}{|c|c|c|c|c|c|c|c|c|c|c|c|c|}
\hline \multirow[b]{3}{*}{$\begin{array}{l}\text { Minutes/ } \\
\text { day }\end{array}$} & \multicolumn{12}{|c|}{ Number of participants (\%) } \\
\hline & \multicolumn{3}{|l|}{ Overall } & \multicolumn{3}{|l|}{ Urban area } & \multicolumn{3}{|c|}{ Suburban area } & \multicolumn{3}{|c|}{ Exurban area } \\
\hline & $\begin{array}{l}\text { Light } \\
\text { activity }\end{array}$ & $\begin{array}{l}\text { Moderate } \\
\text { activity }\end{array}$ & \begin{tabular}{|l|} 
Vigorous \\
activity
\end{tabular} & $\begin{array}{l}\text { Light } \\
\text { activity }\end{array}$ & \begin{tabular}{|l|} 
Moderate \\
activity
\end{tabular} & \begin{tabular}{|l|} 
Vigorous \\
activity
\end{tabular} & $\begin{array}{l}\text { Light } \\
\text { activity }\end{array}$ & $\begin{array}{l}\text { Moderate } \\
\text { activity }\end{array}$ & \begin{tabular}{|l|} 
Vigorous \\
activity
\end{tabular} & $\begin{array}{l}\text { Light } \\
\text { activity }\end{array}$ & $\begin{array}{l}\text { Moderate } \\
\text { activity }\end{array}$ & \begin{tabular}{|l|} 
Vigorous \\
activity
\end{tabular} \\
\hline \multicolumn{13}{|l|}{ Overall } \\
\hline $0-15$ & $3400(32.6)$ & $5584(53.6)$ & $5596(53.7)$ & $1228(31.8)$ & $1999(51.7)$ & $2049(53.0)$ & $1272(34.6)$ & $2093(56.9)$ & $2064(56.1)$ & $900(31.3)$ & $1492(51.9)$ & $1483(51.6)$ \\
\hline $16-30$ & $4313(41.4)$ & $3281(31.5)$ & $3268(31.4)$ & $1587(41.0)$ & $1299(33.6)$ & $1256(32.5)$ & $1526(41.5)$ & $1084(29.5)$ & $1096(29.8)$ & $1200(41.8)$ & $898(31.3)$ & $916(31.9)$ \\
\hline $31-60$ & $2072(19.9)$ & $1155(11.1)$ & $1042(10.0)$ & $801(20.7)$ & $441(11.4)$ & $399(10.3)$ & $677(18.4)$ & $371(10.1)$ & $367(10.0)$ & $594(20.7)$ & $343(11.9)$ & $276(9.6)$ \\
\hline$>60$ & $631(6.1)$ & $396(3.8)$ & $510(4.9)$ & $251(6.5)$ & $128(3.3)$ & $163(4.2)$ & $202(5.5)$ & $129(3.5)$ & $150(4.1)$ & $178(6.2)$ & $139(4.8)$ & $197(6.9)$ \\
\hline \multicolumn{13}{|l|}{ Sex } \\
\hline \multicolumn{13}{|l|}{ Boys } \\
\hline $0-15$ & $1679(32.2)$ & $2720(52.1)$ & $2638(50.5)$ & $562(30.1)$ & $963(51.5)$ & $940(50.3)$ & $650(35.5)$ & $1018(55.6)$ & $977(53.4)$ & $467(30.8)$ & $739(48.7)$ & $721(47.5)$ \\
\hline $16-30$ & $2125(40.7)$ & $1627(31.2)$ & $1645(31.5)$ & $780(41.7)$ & $614(32.8)$ & $622(33.3)$ & $747(40.8)$ & $542(29.6)$ & $546(29.8)$ & $598(39.4)$ & $471(31.0)$ & 477 (31.4) \\
\hline $31-60$ & $1040(19.9)$ & $610(11.7)$ & $592(11.3)$ & $374(20.0)$ & $217(11.6)$ & $208(11.1)$ & $328(17.9)$ & $192(10.5)$ & $210(11.5)$ & $338(22.3)$ & $201(13.2)$ & $174(11.5)$ \\
\hline$>60$ & $375(7.2)$ & $262(5.0)$ & $344(6.6)$ & $154(8.2)$ & $76(4.1)$ & $100(5.3)$ & $106(5.8)$ & $79(4.3)$ & $98(5.4)$ & $115(7.6)$ & $107(7.0)$ & $146(9.6)$ \\
\hline \multicolumn{13}{|l|}{ Girls } \\
\hline $0-15$ & $1721(33.1)$ & $2864(55.1)$ & $2958(56.8)$ & $666(33.4)$ & $1036(51.9)$ & $1109(55.5)$ & $622(33.7)$ & $1075(58.2)$ & $1087(58.9)$ & $433(32.0)$ & $753(55.6)$ & $762(56.3)$ \\
\hline $16-30$ & $2188(42.1)$ & $1654(31.8)$ & $1623(31.2)$ & $807(40.4)$ & $685(34.3)$ & $634(31.7)$ & $779(42.2)$ & $542(29.4)$ & $550(29.8)$ & $602(44.5)$ & 427 (31.5) & $439(32.4)$ \\
\hline $31-60$ & $1032(19.9)$ & $545(10.5)$ & $450(8.7)$ & 427 (21.4) & $224(11.2)$ & $191(9.6)$ & 349 (18.9) & $179(9.7)$ & $157(8.5)$ & $256(18.9)$ & $142(10.5)$ & $102(7.5)$ \\
\hline$>60$ & $256(4.9)$ & $134(2.6)$ & $166(3.2)$ & $97(4.9)$ & $52(2.6)$ & $63(3.2)$ & $96(5.2)$ & $50(2.7)$ & $52(2.8)$ & $63(4.7)$ & $32(2.4)$ & $51(3.8)$ \\
\hline \multicolumn{13}{|l|}{ Grades } \\
\hline \multicolumn{13}{|c|}{ Lower grades of primary school ${ }^{*}$} \\
\hline $0-15$ & $675(29.6)$ & $1034(45.4)$ & $1018(44.7)$ & $267(28.0)$ & $402(42.2)$ & $409(43.0)$ & $223(31.9)$ & $340(48.6)$ & $318(45.4)$ & $185(29.5)$ & $292(46.6)$ & $291(46.4)$ \\
\hline $16-30$ & $1023(44.9)$ & $856(37.6)$ & $954(41.9)$ & $422(44.3)$ & $379(39.8)$ & $415(43.6)$ & $314(44.9)$ & $254(36.3)$ & $296(42.3)$ & $287(45.8)$ & $223(35.6)$ & $243(38.8)$ \\
\hline $31-60$ & 447 (19.6) & $306(13.4)$ & $215(9.4)$ & $210(22.1)$ & $137(14.4)$ & $97(10.2)$ & $120(17.1)$ & $82(11.7)$ & $60(8.6)$ & $117(18.7)$ & $87(13.9)$ & $58(9.3)$ \\
\hline$>60$ & $134(5.9)$ & $83(3.6)$ & $92(4.0)$ & $53(5.6)$ & $34(3.6)$ & $31(3.3)$ & $43(6.1)$ & $24(3.4)$ & $26(3.7)$ & $38(6.1)$ & $25(4.0)$ & $35(5.6)$ \\
\hline \multicolumn{13}{|c|}{ Higher grades of primary school ${ }^{* *}$} \\
\hline $0-15$ & $696(31.6)$ & $1092(49.5)$ & $1099(49.9)$ & $265(28.7)$ & $416(45.0)$ & $433(46.9)$ & $271(37.1)$ & $398(54.4)$ & $370(50.6)$ & $160(29.1)$ & $278(50.6)$ & $296(53.9)$ \\
\hline $16-30$ & $983(44.6)$ & $755(34.3)$ & $784(35.6)$ & $403(43.6)$ & $355(38.4)$ & $349(37.8)$ & $320(43.8)$ & $222(30.4)$ & $258(35.3)$ & $260(47.4)$ & $178(32.4)$ & $177(32.2)$ \\
\hline $31-60$ & $410(18.6)$ & $267(12.1)$ & $206(9.3)$ & $200(21.6)$ & $111(12.0)$ & $92(10.0)$ & $110(15.0)$ & $86(11.8)$ & $75(10.3)$ & $100(18.2)$ & $70(12.8)$ & $39(7.1)$ \\
\hline$>60$ & $115(5.2)$ & $90(4.1)$ & $115(5.2)$ & $56(6.1)$ & $42(4.5)$ & $50(5.4)$ & $30(4.1)$ & $25(3.4)$ & $28(3.8)$ & $29(5.3)$ & $23(4.2)$ & $37(6.7)$ \\
\hline \multicolumn{13}{|c|}{ Secondary school } \\
\hline $0-15$ & $785(27.6)$ & $1366(48.0)$ & $1283(45.1)$ & $270(28.2)$ & $476(49.7)$ & $454(47.4)$ & $234(28.5)$ & $409(49.8)$ & $390(47.4)$ & $281(26.4)$ & $481(45.2)$ & $439(41.3)$ \\
\hline $16-30$ & $1190(41.9)$ & $950(33.4)$ & $962(33.8)$ & $391(40.9)$ & $320(33.4)$ & $308(32.2)$ & $338(41.1)$ & $266(32.4)$ & $257(31.3)$ & $461(43.3)$ & $364(34.2)$ & $397(37.3)$ \\
\hline $31-60$ & $651(22.9)$ & $378(13.3)$ & $392(13.8)$ & $211(22.0)$ & $122(12.7)$ & $134(14.0)$ & $189(23.0)$ & $106(12.9)$ & $123(15.0)$ & $251(23.6)$ & $150(14.1)$ & $135(12.7)$ \\
\hline$>60$ & $217(7.6)$ & $149(5.2)$ & $206(7.2)$ & $85(8.9)$ & $39(4.1)$ & $61(6.4)$ & $61(7.4)$ & $41(5.0)$ & $52(6.3)$ & $71(6.7)$ & $69(6.5)$ & $93(8.7)$ \\
\hline \multicolumn{13}{|c|}{ High school } \\
\hline $0-15$ & $1244(40.3)$ & $2092(67.7)$ & $2196(71.1)$ & $426(41.2)$ & 705 (68.2) & $753(72.8)$ & $544(38.2)$ & $946(66.4)$ & $986(69.2)$ & $274(43.4)$ & $441(69.8)$ & $457(72.3)$ \\
\hline $16-30$ & $1117(36.1)$ & $720(23.3)$ & $568(18.4)$ & $371(35.9)$ & $245(23.7)$ & $184(17.8)$ & $554(38.9)$ & $342(24.0)$ & $285(20.0)$ & $192(30.4)$ & $133(21.0)$ & $99(15.7)$ \\
\hline $31-60$ & $564(18.3)$ & $204(6.6)$ & $229(7.4)$ & $180(17.4)$ & $71(6.9)$ & $76(7.4)$ & $258(18.1)$ & $97(6.8)$ & $109(7.7)$ & $126(19.9)$ & $36(5.7)$ & $44(7.0)$ \\
\hline$>60$ & $165(5.3)$ & $74(2.4)$ & $97(3.1)$ & $57(5.5)$ & $13(1.3)$ & $21(2.0)$ & $68(4.8)$ & $39(2.7)$ & $44(3.1)$ & $40(6.3)$ & $22(3.5)$ & $32(5.1)$ \\
\hline
\end{tabular}

Table 2. Durations of three types of student's physical activities during the COVID-19 pandemic. All data

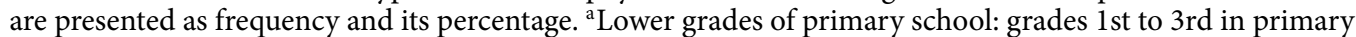
school. ${ }^{b}$ Higher grades of primary school: grades 4 th to 6 th in primary school.

In our survey, we found that $42.3-48.2 \%$ of total students reported more than $5 \mathrm{~h}$ per day on on-line study via digital devices, especially among high school students who had higher pressure for entrance to a better college $^{29}$. Compared to lower grade students, they had to spend longer time on attending on-line classes, finishing homework, and taking the examination through the digital devices during the school closure. Without the stress-reduced effects of physical education participation ${ }^{30}$ and peer connectedness ${ }^{29}$, the heavy workload might associated with greater distress and negative $\operatorname{mood}^{31}$, then might exacerbate or trigger underlying stress vulnerability among high school students during the suspend of classes.

Over $50 \%$ of students spent over one hour per day in amusement and leisure. Under the home confinement, students might spend more time in using screen-based media to pass the time ${ }^{32}$. Without adult supervision, children might be exposed to an open-ended periods of screen time due to less regulation or restriction ${ }^{33}$, especially for the high school students who had limited opportunities to play video games or watch TV in school. The screen time for majority of students exceeded the screen-based recommendations of less than $2 \mathrm{~h}$ screening time per day ${ }^{34}$. A series of symptoms (eye fatigue, blurred vision, or eye dryness) could be caused by excessive computer screen exposure $e^{35}$, and myopia was the primary concern after long screen time ${ }^{36}$. Compared those 


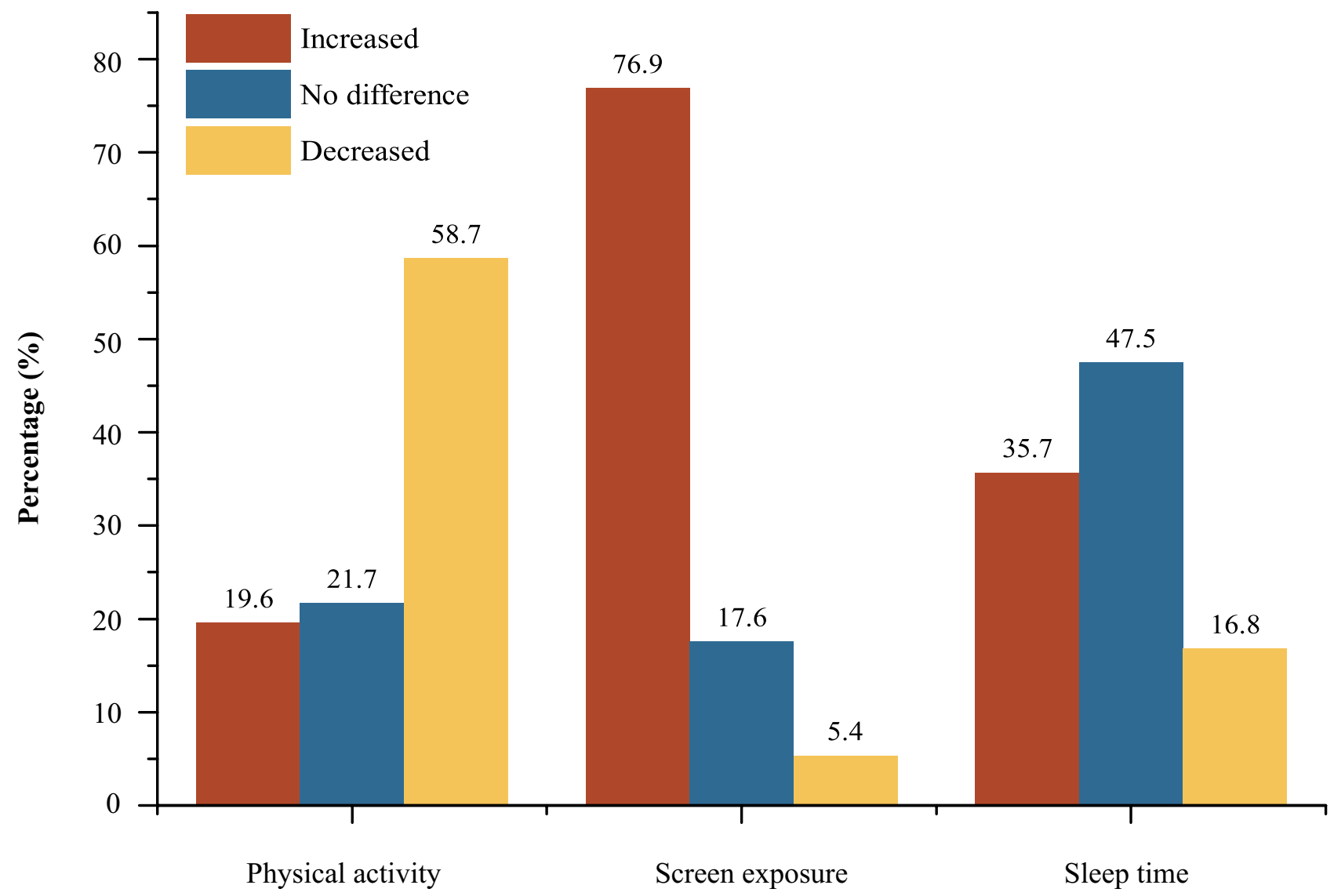

Figure 2. Changes in durations of physical activity, screen exposure and sleep time in students after the outbreak of COVID-19.

exposing to screen devices $<2 \mathrm{~h} /$ day, using screen devices over $6 \mathrm{~h} /$ day induced about doubled risk of suffering myopia $^{36}$. In addition, excessive and addictive use of digital media might be associated with obesity ${ }^{37}$, reduced bone density ${ }^{35}$, poor sleep ${ }^{38}$, and even damaged psychosocial health in youths ${ }^{39}$.

Our study also indicated that children's sleep become irregular during the crisis. The reason might be due to that, the students were given more freedom to stay up late at night and wake up late in the morning during the less-structed days in response to the school closure. In addition, increased risk of irregular sleep pattern occurred when students were out of school ${ }^{4}$. During the school days, most of students had to go to bed earlier and wake up on time to meet the need of attending school ${ }^{21}$. However, previous study provided supporting evidence that child's bed/wake-times might be later in weekend than that in weekends ${ }^{40}$. Irregular sleeping duration might worsen children's physical and mental conditions ${ }^{41}$, as well as academic performance ${ }^{42}$. Reduced sleep might also exert negative effects on children's health, such as overweight/obesity and depressive symptoms ${ }^{43,44}$.

The strength of the present epidemiologic study is the relatively large sample size. However, the limitations of this study should be acknowledged. Firstly, conducting through an online questionnaire during the pandemic of COVID-19, this survey was inevitable to subject to nonresponse bias. Secondly, in order to ensure the timeliness and conciseness of the questionnaire survey, the authors conducted this survey even though some specific questions were not specifically validated. Thirdly, in order to collect the valuable information as soon as possible in this critical period, as well as maintaining the compliance of participants, there might be some important factors have not been included in our study aside from the basic demographic information such as gender, age and grades. Fourthly, the quality of the respondents was determined by student's grades, thus the recall bias might be caused by the inconsistent responders. We tried to reduce this bias through suggesting caregivers to supervise and explanate each question for students from all grades during the fulfilling of our questionnaire. Fifthly, there might be selection bias because all the included schools were not randomly selected; however, we included a relatively large number of students from primary, secondary, and high schools from three different districts to minimize the potential influence of sampling. Finally, the samples were only recruited from schools in Guangzhou, one of the most developed regions in China. Our findings generalized to other cities or countries should be with caution.

\section{Conclusion}

Taken together, findings from this survey revealed that the school closure during the COVID-19 pandemic might have several adverse impacts on the healthy lifestyle habits of school-aged children and adolescents, including decreased engagement in physical activity, longer screen exposure and irregular sleeping duration. 


\begin{tabular}{|c|c|c|c|c|c|c|c|c|c|c|c|c|}
\hline \multirow[b]{3}{*}{ Hours/day } & \multicolumn{12}{|c|}{ Number of participants (\%) } \\
\hline & \multicolumn{3}{|c|}{ Overall } & \multicolumn{3}{|l|}{ Urban area } & \multicolumn{3}{|c|}{ Suburban area } & \multicolumn{3}{|c|}{ Exurban area } \\
\hline & Study & Amusement & Leisure & Study & Amusement & Leisure & Study & Amusement & Leisure & Study & Amusement & Leisure \\
\hline \multicolumn{13}{|l|}{ Overall } \\
\hline None & $84(0.8)$ & $3649(35.0)$ & $1582(15.2)$ & $23(0.6)$ & $1436(37.1)$ & $588(15.2)$ & $27(0.7)$ & $1293(35.2)$ & $550(15.0)$ & $34(1.2)$ & $920(32.0)$ & $444(15.5)$ \\
\hline $0-0.5$ & $227(2.2)$ & $2465(23.7)$ & $2880(27.6)$ & $54(1.4)$ & $919(23.8)$ & $1089(28.2)$ & $106(2.9)$ & $913(24.8)$ & $1070(29.1)$ & $67(2.3)$ & $633(22.0)$ & $721(25.1)$ \\
\hline $1-2$ & $2977(28.6)$ & $3646(35.0)$ & $5198(49.9)$ & $942(24.4)$ & $1298(33.6)$ & $1904(49.2)$ & $1177(32.0)$ & $1246(33.9)$ & $1804(49.1)$ & $858(29.9)$ & $1102(38.4)$ & $1490(51.9)$ \\
\hline $3-4$ & $2479(23.8)$ & $461(4.4)$ & $499(4.8)$ & $986(25.5)$ & $148(3.8)$ & $189(4.9)$ & $810(22.0)$ & $160(44.0)$ & $179(4.9)$ & $683(23.8)$ & $153(5.3)$ & $131(4.6)$ \\
\hline$\geq 5$ & $4649(44.6)$ & $195(1.9)$ & $257(2.5)$ & $1862(48.2)$ & $66(1.7)$ & $97(2.5)$ & $1557(42.3)$ & $65(1.8)$ & $74(2.0)$ & $1230(42.8)$ & $64(2.2)$ & $86(3.0)$ \\
\hline \multicolumn{13}{|l|}{ Sex } \\
\hline \multicolumn{13}{|l|}{ Boys } \\
\hline None & $48(0.9)$ & $1336(25.6)$ & $925(17.7)$ & $7(0.4)$ & $529(28.3)$ & $336(18.0)$ & $19(1.0)$ & $476(26.0)$ & $326(17.8)$ & $22(1.4)$ & $331(21.8)$ & $263(17.3)$ \\
\hline $0-0.5$ & $137(2.6)$ & $1229(23.5)$ & 1439 (27.6) & $36(1.9)$ & $455(24.3)$ & $540(28.9)$ & $64(3.5)$ & $448(24.5)$ & $524(28.6)$ & $37(2.4)$ & $326(21.5)$ & $375(24.7)$ \\
\hline $1-2$ & $1614(30.9)$ & 2177 (41.7) & 2477 (47.5) & $500(26.7)$ & $743(39.7)$ & 853 (45.6) & $638(34.8)$ & 744 (40.6) & $859(46.9)$ & $476(31.4)$ & $690(45.5)$ & $765(50.4)$ \\
\hline $3-4$ & $1267(24.3)$ & $335(6.4)$ & $224(4.3)$ & $508(27.2)$ & $100(5.3)$ & $88(4.7)$ & $391(21.4)$ & $114(6.2)$ & $78(4.3)$ & $368(24.2)$ & $121(8.0)$ & $58(3.8)$ \\
\hline$\geq 5$ & $2153(41.3)$ & $142(2.7)$ & $154(3.0)$ & $819(43.8)$ & $43(2.3)$ & $53(2.8)$ & $719(39.3)$ & $49(2.7)$ & $44(2.4)$ & $615(40.5)$ & $50(3.3)$ & $57(3.8)$ \\
\hline \multicolumn{13}{|l|}{ Girls } \\
\hline None & $36(0.7)$ & $2313(44.5)$ & $657(12.6)$ & $16(0.8)$ & $907(45.4)$ & $252(12.6)$ & $8(0.4)$ & $817(44.3)$ & $224(12.1)$ & $12(0.9)$ & $589(43.5)$ & $181(13.4)$ \\
\hline $0-0.5$ & $90(1.7)$ & $1236(23.8)$ & $1441(27.7)$ & $18(0.9)$ & $464(23.2)$ & $549(27.5)$ & $42(2.3)$ & 465 (25.2) & $546(29.6)$ & $30(2.2)$ & $307(22.7)$ & $346(25.6)$ \\
\hline $1-2$ & $1363(26.2)$ & $1469(28.3)$ & $2721(52.4)$ & $442(22.1)$ & $555(27.8)$ & $1051(52.6)$ & $539(29.2)$ & $502(27.2)$ & $945(51.2)$ & $382(28.2)$ & $412(30.4)$ & $725(53.5)$ \\
\hline $3-4$ & $1212(23.3)$ & $126(2.4)$ & $275(5.3)$ & $478(23.9)$ & $48(2.4)$ & $101(5.1)$ & $419(22.7)$ & $46(2.5)$ & $101(5.5)$ & $315(23.3)$ & $32(2.4)$ & $73(5.4)$ \\
\hline$\geq 5$ & $2496(48.0)$ & $53(1.0)$ & $103(2.0)$ & $1043(52.2)$ & $23(1.2)$ & $44(2.2)$ & $838(45.4)$ & $16(0.9)$ & $30(1.6)$ & $615(45.4)$ & $14(1.0)$ & $29(2.1)$ \\
\hline \multicolumn{13}{|l|}{ Grades } \\
\hline \multicolumn{13}{|c|}{ Lower grades of primary school ${ }^{\mathrm{a}}$} \\
\hline None & $26(1.1)$ & $1013(44.4)$ & $592(26.0)$ & $8(0.8)$ & $419(44.0)$ & $245(25.7)$ & $5(0.7)$ & $337(48.1)$ & $194(27.7)$ & $13(2.1)$ & $257(41.0)$ & $153(24.4)$ \\
\hline $0-0.5$ & $106(4.7)$ & $565(24.8)$ & $584(25.6)$ & $27(2.8)$ & $229(24.1)$ & $255(26.8)$ & $60(8.6)$ & $172(24.6)$ & $191(27.3)$ & $19(3.0)$ & $164(26.2)$ & $138(22.0)$ \\
\hline $1-2$ & $1360(59.7)$ & $619(27.2)$ & $1014(44.5)$ & $490(51.5)$ & $270(28.4)$ & $417(43.8)$ & $488(69.7)$ & $163(23.3)$ & $286(40.9)$ & $382(60.9)$ & $186(29.7)$ & $311(49.6)$ \\
\hline $3-4$ & $628(27.6)$ & $65(2.9)$ & $64(2.8)$ & $327(34.3)$ & $24(2.5)$ & $26(2.7)$ & $128(18.3)$ & $24(3.4)$ & $21(3.0)$ & $173(27.6)$ & $17(2.7)$ & $17(2.7)$ \\
\hline$\geq 5$ & $159(7.0)$ & $17(0.7)$ & $25(1.1)$ & $100(10.5)$ & $10(1.1)$ & $9(0.9)$ & $19(2.7)$ & $4(0.6)$ & $8(1.1)$ & $40(6.4)$ & $3(0.5)$ & $8(1.3)$ \\
\hline \multicolumn{13}{|c|}{ Higher grades of primary school ${ }^{\mathrm{b}}$} \\
\hline None & $18(0.8)$ & $770(34.9)$ & $347(15.7)$ & $9(1.0)$ & $345(37.3)$ & $152(16.5)$ & $5(0.7)$ & $232(31.7)$ & $110(15.0)$ & $4(0.7)$ & $193(35.2)$ & $85(15.5)$ \\
\hline $0-0.5$ & $63(2.9)$ & $536(24.3)$ & $636(28.9)$ & $19(2.1)$ & $223(24.1)$ & $273(29.5)$ & $26(3.6)$ & $187(25.6)$ & $217(29.7)$ & $18(3.3)$ & $126(23.0)$ & $146(26.6)$ \\
\hline $1-2$ & $1089(49.4)$ & $746(33.8)$ & $1078(48.9)$ & $331(35.8)$ & $297(32.1)$ & $442(47.8)$ & $482(65.9)$ & $251(34.3)$ & $354(48.4)$ & $276(50.3)$ & $198(36.1)$ & $282(51.4)$ \\
\hline $3-4$ & $739(33.5)$ & $116(5.3)$ & $108(4.9)$ & $363(39.3)$ & $49(5.3)$ & $41(4.4)$ & $177(24.2)$ & $42(5.7)$ & $40(5.5)$ & $199(36.2)$ & $25(4.6)$ & $27(4.9)$ \\
\hline$\geq 5$ & $295(13.4)$ & $36(1.6)$ & $35(1.6)$ & $202(21.9)$ & $10(1.1)$ & $16(1.7)$ & $41(5.6)$ & $19(2.6)$ & $10(1.4)$ & $52(9.5)$ & $7(1.3)$ & $9(1.6)$ \\
\hline \multicolumn{13}{|c|}{ Secondary school } \\
\hline None & $21(0.7)$ & $836(29.4)$ & $349(12.3)$ & $5(0.5)$ & $301(31.5)$ & $103(10.8)$ & $5(0.6)$ & $270(32.8)$ & $120(14.6)$ & $11(1.0)$ & $265(24.9)$ & $126(11.8)$ \\
\hline $0-0.5$ & $41(1.4)$ & $641(22.5)$ & $775(27.3)$ & $5(0.5)$ & $209(21.8)$ & $244(25.5)$ & $9(1.1)$ & $209(25.4)$ & $257(31.3)$ & $27(2.5)$ & $223(21.0)$ & $274(25.8)$ \\
\hline $1-2$ & $374(13.2)$ & $1130(39.7)$ & $1442(50.7)$ & $94(9.8)$ & $371(38.8)$ & $496(51.8)$ & $112(13.6)$ & $297(36.1)$ & $387(47.1)$ & $168(15.8)$ & $462(43.4)$ & $559(52.5)$ \\
\hline $3-4$ & $714(25.1)$ & $158(5.6)$ & $167(5.9)$ & $212(22.2)$ & $51(5.3)$ & $73(7.6)$ & $247(30.0)$ & $30(3.6)$ & $37(4.5)$ & $255(24.0)$ & $77(7.2)$ & $57(5.4)$ \\
\hline$\geq 5$ & $1693(59.5)$ & $78(2.7)$ & $110(3.9)$ & $641(67.0)$ & $25(2.6)$ & $41(4.3)$ & $449(54.6)$ & $16(1.9)$ & $21(2.6)$ & $603(56.7)$ & $37(3.5)$ & $48(4.5)$ \\
\hline \multicolumn{13}{|c|}{ High school } \\
\hline None & $19(0.6)$ & $1030(33.3)$ & $294(9.5)$ & $1(0.1)$ & $371(35.9)$ & $88(8.5)$ & $12(0.8)$ & $454(31.9)$ & $126(8.8)$ & $6(0.9)$ & $205(32.4)$ & $80(12.7)$ \\
\hline $0-0.5$ & $17(0.6)$ & $723(23.4)$ & $885(28.6)$ & $3(0.3)$ & $258(25.0)$ & $317(30.7)$ & $11(0.8)$ & $345(24.2)$ & $405(28.4)$ & $3(0.5)$ & $120(19.0)$ & $163(25.8)$ \\
\hline $1-2$ & $154(5.0)$ & $1151(37.2)$ & $1664(53.9)$ & $27(2.6)$ & $360(34.8)$ & $549(53.1)$ & $95(6.7)$ & $535(37.6)$ & $777(54.6)$ & $32(5.1)$ & $256(40.5)$ & $338(53.5)$ \\
\hline $3-4$ & $398(12.9)$ & $122(3.9)$ & $160(5.2)$ & $84(8.1)$ & $24(2.3)$ & $49(4.7)$ & $258(18.1)$ & $64(4.5)$ & $81(5.7)$ & $\begin{array}{r}56 \\
(8.9) \\
\end{array}$ & $34(5.4)$ & $30(4.7)$ \\
\hline$\geq 5$ & $2502(81.0)$ & $64(2.1)$ & $87(2.8)$ & $919(88.9)$ & $21(2.0)$ & $31(3.0)$ & $1048(73.6)$ & $26(1.8)$ & $35(2.5)$ & $535(84.7)$ & $17(2.7)$ & $21(3.3)$ \\
\hline
\end{tabular}

Table 3. Daily screen time for three purposes among students during the COVID-19 pandemic. All data

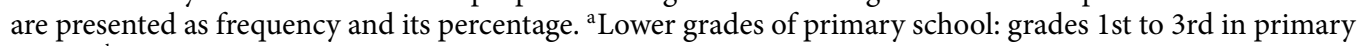
school. ${ }^{b}$ Higher grades of primary school: grades 4 th to 6 th in primary school.

However, according to guidance recommended by the National Health Commission of the People's Republic of China during the pandemic of COVID-1945, school-aged children should do $2 \mathrm{~h}$ or more of outdoor exercises and $30 \mathrm{~min}$ recess physical activity daily. Daily screen time for online learning should be limited within $2.5 \mathrm{~h}$ for students from primary schools and $4 \mathrm{~h}$ for students from secondary and high schools, and screen time for other purposes should be limited to within $1 \mathrm{~h}$ per day. Students from primary, secondary, and high schools should sleep no less than 10, 9 and 8 h daily, respectively. Hence, close attention and great efforts are required 


\begin{tabular}{|c|c|c|c|c|}
\hline & \multicolumn{4}{|c|}{ Number of participants (\%) } \\
\hline & Overall & Urban area & Suburban area & Exurban area \\
\hline \multicolumn{5}{|l|}{ Overall } \\
\hline Inadequate sleep & $4011(38.5)$ & $1606(41.5)$ & $1231(33.5)$ & $1174(40.9)$ \\
\hline Adequate sleep & $6189(59.4)$ & $2190(56.6)$ & $2367(64.4)$ & $1632(56.8)$ \\
\hline Excessive sleep & $216(2.1)$ & $71(1.8)$ & $79(2.1)$ & $66(2.3)$ \\
\hline \multicolumn{5}{|l|}{ Sex } \\
\hline \multicolumn{5}{|l|}{ Boys } \\
\hline Inadequate sleep & $1932(37.0)$ & $738(39.5)$ & $590(32.2)$ & $604(39.8)$ \\
\hline Adequate sleep & $3166(60.7)$ & $1090(58.3)$ & $1197(65.4)$ & $879(57.9)$ \\
\hline Excessive sleep & $121(2.3)$ & $42(2.2)$ & $44(2.4)$ & $35(2.3)$ \\
\hline \multicolumn{5}{|l|}{ Girls } \\
\hline Inadequate sleep & $2079(40.0)$ & $868(43.5)$ & $641(34.7)$ & $570(42.1)$ \\
\hline Adequate sleep & $3023(58.2)$ & $1100(55.1)$ & $1170(63.4)$ & $753(55.6)$ \\
\hline Excessive sleep & $95(1.8)$ & $29(1.5)$ & $35(1.9)$ & $31(2.3)$ \\
\hline \multicolumn{5}{|l|}{ Grades } \\
\hline \multicolumn{5}{|c|}{ Lower grades of primary school $^{a}$} \\
\hline Inadequate sleep & $594(26.1)$ & $218(22.9)$ & $159(22.7)$ & $217(34.6)$ \\
\hline Adequate sleep & $1664(73.0)$ & $723(75.9)$ & $533(76.1)$ & $408(65.1)$ \\
\hline Excessive sleep & $21(0.9)$ & $11(1.2)$ & $8(1.1)$ & $2(0.3)$ \\
\hline \multicolumn{5}{|c|}{ Higher grades of primary school ${ }^{\mathrm{b}}$} \\
\hline Inadequate sleep & $836(37.9)$ & $337(36.5)$ & $249(34.1)$ & $250(45.5)$ \\
\hline Adequate sleep & $1354(61.4)$ & $582(63.0)$ & $475(65.0)$ & $297(54.1)$ \\
\hline Excessive sleep & $14(0.6)$ & $5(0.5)$ & $7(1.0)$ & $2(0.4)$ \\
\hline \multicolumn{5}{|l|}{ Secondary school } \\
\hline Inadequate sleep & $822(28.9)$ & $303(31.7)$ & $182(22.1)$ & $337(31.7)$ \\
\hline Adequate sleep & $1893(66.6)$ & $609(63.6)$ & $606(73.7)$ & $678(63.7)$ \\
\hline Excessive sleep & $128(4.5)$ & $45(4.7)$ & $34(4.1)$ & $49(4.6)$ \\
\hline \multicolumn{5}{|l|}{ High school } \\
\hline Inadequate sleep & $1759(56.9)$ & $748(72.3)$ & $641(45.0)$ & $370(58.5)$ \\
\hline Adequate sleep & $1278(41.4)$ & $276(26.7)$ & $753(52.9)$ & $249(39.4)$ \\
\hline Excessive sleep & $53(1.7)$ & $10(1.0)$ & $30(2.1)$ & $13(2.1)$ \\
\hline
\end{tabular}

Table 4. Sleeping evaluation among students in various regions during the COVID-19 pandemic. All data are presented as frequency and its percentage. ${ }^{a}$ Lower grades of primary school: grades 1st to 3rd in primary school. ${ }^{b}$ Higher grades of primary school: grades 4 th to 6 th in primary school.

to address these issues timely under the control of this pandemic, including offering more opportunities for physical activity, providing guidelines to limit screen exposure and to maintain regular sleeping pattern among school-aged children and adolescents.

\section{Data availability}

The datasets during and/or analysed during the current study available from the corresponding author on reasonable request.

Received: 22 October 2020; Accepted: 22 March 2021

Published online: 20 April 2021

\section{References}

1. Zhu, N. et al. A novel coronavirus from patients with pneumonia in China, 2019. N. Engl. J. Med. 382, 727-733. https://doi.org/ 10.1056/NEJMoa2001017 (2020).

2. World Health Organization. Coronavirus Disease (COVID-19) Pandemic (WHO, 2021).

3. Viner, R. M. et al. School closure and management practices during coronavirus outbreaks including COVID-19: A rapid systematic review. Lancet Child Adolesc. Health. https://doi.org/10.1016/s2352-4642(20)30095-x (2020).

4. Wang, G., Zhang, Y., Zhao, J., Zhang, J. \& Jiang, F. Mitigate the effects of home confinement on children during the COVID-19 outbreak. Lancet 395, 945-947. https://doi.org/10.1016/s0140-6736(20)30547-x (2020).

5. CCTV News. Ministry of Education: National Elementary and Middle School Network Cloud Platform Opens for Free Use Today (2020). http://www.chinanews.com/sh/2020/02-17/9094648.shtml.

6. Li, Y. et al. The temporal association of introducing and lifting non-pharmaceutical interventions with the time-varying reproduction number (R) of SARS-CoV-2: A modelling study across 131 countries. Lancet Infect. Dis. https://doi.org/10.1016/s14733099(20)30785-4 (2021). 
7. Rundle, A. G., Park, Y., Herbstman, J. B., Kinsey, E. W. \& Wang, Y. C. COVID-19 related school closings and risk of weight gain among children. Obesity (Silver Spring) https://doi.org/10.1002/oby.22813 (2020).

8. Jiao, W. Y. et al. Behavioral and emotional disorders in children during the COVID-19 epidemic. J. Pediatr. https://doi.org/10. 1016/j.jpeds.2020.03.013 (2020).

9. Cao, W. et al. The psychological impact of the COVID-19 epidemic on college students in China. Psychiatry Res. 287, 112934. https://doi.org/10.1016/j.psychres.2020.112934 (2020).

10. Tang, W. et al. Prevalence and correlates of PTSD and depressive symptoms one month after the outbreak of the COVID-19 epidemic in a sample of home-quarantined Chinese university students. J. Affect. Disord. 274, 1-7. https://doi.org/10.1016/j.jad. 2020.05.009 (2020).

11. Choi, B. et al. The impact of the COVID-19 pandemic on final year medical students in the United Kingdom: A national survey. BMC Med. Educ. 20, 206. https://doi.org/10.1186/s12909-020-02117-1 (2020).

12. Franchi, T. The impact of the covid-19 pandemic on current anatomy education and future careers: A student's perspective. Anat. Sci. Educ. 13, 312-315. https://doi.org/10.1002/ase.1966 (2020).

13. López-Bueno, R. et al. Health-related behaviors among school-aged children and adolescents during the Spanish covid-19 confinement. Front. Pediatr. 8, 573. https://doi.org/10.3389/fped.2020.00573 (2020).

14. Thorn, J. E., DeLellis, N., Chandler, J. P. \& Boyd, K. Parent and child self-reports of dietary behaviors, physical activity, and screen time. J. Pediatr. 162, 557-561. https://doi.org/10.1016/j.jpeds.2012.08.031 (2013).

15. Luo, H., Lie, Y. \& Prinzen, F. W. Surveillance of COVID-19 in the general population using an online questionnaire: Report from 18,161 respondents in China. JMIR Public Health Surveill. 6, e18576. https://doi.org/10.2196/18576 (2020).

16. Paruthi, S. et al. Consensus statement of the American Academy of sleep medicine on the recommended amount of sleep for healthy children: Methodology and discussion. J. Clin. Sleep Med. 12, 1549-1561. https://doi.org/10.5664/jcsm.6288 (2016).

17. Moore, S. A. et al. Impact of the COVID-19 virus outbreak on movement and play behaviours of Canadian children and youth: A national survey. Int. J. Behav. Nutr. Phys. Act. 17, 85. https://doi.org/10.1186/s12966-020-00987-8 (2020).

18. Ruíz-Roso, M. B. et al. Changes of physical activity and ultra-processed food consumption in adolescents from different countries during covid-19 pandemic: An observational study. Nutrients 12, 2289. https://doi.org/10.3390/nu12082289 (2020).

19. Beets, M. W. et al. The theory of expanded, extended, and enhanced opportunities for youth physical activity promotion. Int. J. Behav. Nutr. Phys. Act. 13, 120. https://doi.org/10.1186/s12966-016-0442-2 (2016).

20. Haapala, H. L. et al. Recess physical activity and school-related social factors in Finnish primary and lower secondary schools: Cross-sectional associations. BMC Public Health 14, 1114. https://doi.org/10.1186/1471-2458-14-1114 (2014).

21. Brazendale, K. et al. Understanding differences between summer vs. school obesogenic behaviors of children: The structured days hypothesis. Int. J. Behav. Nutr. Phys. Act. 14, 100. https://doi.org/10.1186/s12966-017-0555-2 (2017).

22. Hallal, P. C. et al. Global physical activity levels: Surveillance progress, pitfalls, and prospects. Lancet 380, 247-257. https://doi. org/10.1016/s0140-6736(12)60646-1 (2012).

23. Seidu, A. A. et al. Are senior high school students in Ghana meeting WHO's recommended level of physical activity? Evidence from the 2012 global school-based student health survey data. PLoS ONE 15, e0229012. https://doi.org/10.1371/journal.pone. $0229012(2020)$.

24. Piercy, K. L. et al. The physical activity guidelines for Americans. JAMA 320, 2020-2028. https://doi.org/10.1001/jama.2018.14854 (2018).

25. Giroir, B. P. \& Wright, D. Physical activity guidelines for health and prosperity in the United States. JAMA 320, 1971-1972. https:// doi.org/10.1001/jama.2018.16998 (2018).

26. Hallal, P. C., Martins, R. C. \& Ramirez, A. The lancet physical activity observatory: Promoting physical activity worldwide. Lancet 384, 471-472. https://doi.org/10.1016/s0140-6736(14)61321-0 (2014).

27. Korczak, D. J., Madigan, S. \& Colasanto, M. Children's physical activity and depression: A meta-analysis. Pediatrics 139, e20162266. https://doi.org/10.1542/peds.2016-2266 (2017).

28. Chen, P. et al. Coronavirus disease (COVID-19): The need to maintain regular physical activity while taking precautions. J. Sport Health Sci. 9, 103-104. https://doi.org/10.1016/j.jshs.2020.02.001 (2020).

29. Wuthrich, V. M., Jagiello, T. \& Azzi, V. Academic stress in the final years of school: A systematic literature review. Child Psychiatry Hum. Dev. https://doi.org/10.1007/s10578-020-00981-y (2020).

30. Park, S., Park, S. Y., Jang, S. Y., Oh, G. \& Oh, I. H. The neglected role of physical education participation on suicidal ideation and stress in high school adolescents from South Korea. Int. J. Environ. Res. Public Health 17, 2838. https://doi.org/10.3390/ijerph1708 $2838(2020)$.

31. Peluso, M. A., Savalli, C., Curi, M., Gorenstein, C. \& Andrade, L. H. Mood changes in the course of preparation for the Brazilian university admission exam - A longitudinal study. Braz. J. Psychiatry 32, 30-36. https://doi.org/10.1590/s1516-444620100001000 07 (2010).

32. Fletcher, E. et al. Is the relationship between sedentary behaviour and cardiometabolic health in adolescents independent of dietary intake? A systematic review. Obes. Rev. 16, 795-805. https://doi.org/10.1111/obr.12302 (2015).

33. Franckle, R., Adler, R. \& Davison, K. Accelerated weight gain among children during summer versus school year and related racial/ ethnic disparities: A systematic review. Prev. Chronic Dis. 11, E101. https://doi.org/10.5888/pcd11.130355 (2014).

34. Barlow, S. E. Expert committee recommendations regarding the prevention, assessment, and treatment of child and adolescent overweight and obesity: Summary report. Pediatrics 120(Suppl 4), S164-192. https://doi.org/10.1542/peds.2007-2329C (2007).

35. Lissak, G. Adverse physiological and psychological effects of screen time on children and adolescents: Literature review and case study. Environ. Res. 164, 149-157. https://doi.org/10.1016/j.envres.2018.01.015 (2018).

36. Hansen, M. H. et al. Low physical activity and higher use of screen devices are associated with myopia at the age of 16-17 years in the CCC2000 eye study. Acta Ophthalmol. 98, 315-321. https://doi.org/10.1111/aos.14242 (2020).

37. Robinson, T. N. et al. Screen media exposure and obesity in children and adolescents. Pediatrics 140, S97-S101. https://doi.org/ 10.1542/peds.2016-1758K (2017).

38. Parent, J., Sanders, W. \& Forehand, R. Youth screen time and behavioral health problems: The role of sleep duration and disturbances. J. Dev. Behav. Pediatr. 37, 277-284. https://doi.org/10.1097/dbp.0000000000000272 (2016).

39. Tremblay, M. S. et al. Systematic review of sedentary behaviour and health indicators in school-aged children and youth. Int. J. Behav. Nutr. Phys. Act. 8, 98. https://doi.org/10.1186/1479-5868-8-98 (2011).

40. Blader, J. C., Koplewicz, H. S., Abikoff, H. \& Foley, C. Sleep problems of elementary school children. A community survey. Arch. Pediatr. Adolesc. Med. 151, 473-480. https://doi.org/10.1001/archpedi.1997.02170420043007 (1997).

41. Fukuda, K., Hasegawa, T., Kawahashi, I. \& Imada, S. Preschool children's eating and sleeping habits: Late rising and brunch on weekends is related to several physical and mental symptoms. Sleep Med. 61, 73-81. https://doi.org/10.1016/j.sleep.2019.03.023 (2019).

42. Asarnow, L. D., McGlinchey, E. \& Harvey, A. G. The effects of bedtime and sleep duration on academic and emotional outcomes in a nationally representative sample of adolescents. J. Adolesc. Health 54, 350-356. https://doi.org/10.1016/j.jadohealth.2013.09. 004 (2014).

43. Olds, T. S., Maher, C. A. \& Matricciani, L. Sleep duration or bedtime? Exploring the relationship between sleep habits and weight status and activity patterns. Sleep 34, 1299-1307. https://doi.org/10.5665/sleep.1266 (2011). 
44. Liu, B. P. et al. Depressive symptoms are associated with short and long sleep duration: A longitudinal study of Chinese adolescents. J. Affect. Disord. 263, 267-273. https://doi.org/10.1016/j.jad.2019.11.113 (2020).

45. Bureau, H. D. C. Guidance on the Prevention of Myopia in Guidance and Adolescents During the Pandemic of COVID-19 (Updated) (2020). http://www.nhc.gov.cn/xcs/yqfkdt/202004/8258621038d346659a64c69b06f46405.shtml. Accessed 2 May 2020.

\section{Author contributions}

Z.F.F. conceived the research and designed the study. G.Y.F. and L.M.Q. analysed the data, drafted and finalized the manuscript; C.W.L. and Y.X.X. contributed to define the scope of the study; L.S.N., K.X.Y., T.S.X., L.Z.Y., C.Y.F. and W.Q. conducted study and completed data entry at study sites; G.X.P, L.J participated in data coding, analysis and interpretation of results; G.Y.F., L.Y.H. and Z.S.: critically reviewed the manuscript. All authors approved the final manuscript as submitted and agreed to be accountable for all aspects of the work.

\section{Funding}

The funding was provided by National Natural Science Foundation of China (81602853).

\section{Competing interests}

The authors declare no competing interests.

\section{Additional information}

Supplementary Information The online version contains supplementary material available at https://doi.org/ 10.1038/s41598-021-88071-4.

Correspondence and requests for materials should be addressed to F.Z.

Reprints and permissions information is available at www.nature.com/reprints.

Publisher's note Springer Nature remains neutral with regard to jurisdictional claims in published maps and institutional affiliations.

Open Access This article is licensed under a Creative Commons Attribution 4.0 International License, which permits use, sharing, adaptation, distribution and reproduction in any medium or format, as long as you give appropriate credit to the original author(s) and the source, provide a link to the Creative Commons licence, and indicate if changes were made. The images or other third party material in this article are included in the article's Creative Commons licence, unless indicated otherwise in a credit line to the material. If material is not included in the article's Creative Commons licence and your intended use is not permitted by statutory regulation or exceeds the permitted use, you will need to obtain permission directly from the copyright holder. To view a copy of this licence, visit http://creativecommons.org/licenses/by/4.0/.

(C) The Author(s) 2021 